Research Article

\title{
Analysis on Flexural Capacity of Square Steel Tube Truss Concrete Beams with Grouted Chords
}

\author{
Kun Wang $\mathbb{D},{ }^{1,2,3}$ Zhiyu Zhu $\mathbb{D}^{1},{ }^{1}$ Huihui Luo $\mathbb{D}^{4},{ }^{4}$ and Ahmed Ahmad Omar $\mathbb{D}^{1}$ \\ ${ }^{1}$ College of Civil Science and Engineering, Yangzhou University, Yangzhou 225127, China \\ ${ }^{2}$ Hunan Province Engineering Laboratory of Bridge Structure (CSUST), Changsha 410015, China \\ ${ }^{3}$ Jiangsu Hanjian Group Company Limited, Yangzhou 225000, China \\ ${ }^{4}$ College of Guangling, Yangzhou University, Yangzhou 225127, China \\ Correspondence should be addressed to Huihui Luo; 060137@yzu.edu.cn
}

Received 28 October 2020; Revised 29 December 2020; Accepted 8 January 2021; Published 12 February 2021

Academic Editor: Shazim A. Memon

Copyright $\odot 2021$ Kun Wang et al. This is an open access article distributed under the Creative Commons Attribution License, which permits unrestricted use, distribution, and reproduction in any medium, provided the original work is properly cited.

\begin{abstract}
In this research paper, simulations on five specimens of square steel tube truss concrete beams with grouted chords were conducted by finite element analysis (FEA) software ABAQUS. Comparison of failure modes, vertical load-deflection curves, and steel tube strain variation with tests was done. The rationality and validity of the FEA models were also verified. On this basis, parameter analysis was carried out, and the influence of concrete strength, steel ratio of upper and lower chords, and spacing of steel tube truss joints on the vertical load-deflection curves were obtained. From the results of tests and parameter analysis, design formulae of flexural bearing capacity for composite beams were proposed based on the assumption that steel tubes are equivalent to ordinary longitudinal steel bars. Accordingly, the results indicated that the steel tubes of the upper chords in the composite beams cannot get yield for full sections due to the structural requirements; the steel tube of the lower chords will be the first to reach fully yielding and the upper concrete crushed subsequently, showing a failure mode analogous to that of the underreinforced concrete beam; the steel ratio of lower chords is the primary factor affecting the flexural capacity of the normal section among the parameters; the calculation from the proposed design formulae for the flexural capacity of normal section is in agreement with the tests and simulations. This research could provide reference for the design of this kind of composite beam.
\end{abstract}

\section{Introduction}

Square steel tube truss concrete beams belong to a kind of steel-concrete composite component which is fabricated by replacing longitudinal steel bars with upper and lower chords and replacing stirrups with vertical and oblique web members of square steel tube truss. In order to avoid cave-in failure, the upper and lower chords of steel tube trusses are usually grouted with cement paste $[1,2]$. Compared to ordinary reinforced concrete beams, square steel tube truss concrete beams have the advantages of higher load-carrying capacity, larger stiffness, and better integrity performance. Consequently, making them suitable for long-span, heavyload, and prefabricated building structures. Steel tube trusses can be prefabricated in the factory, transported to the construction site, and placed in the framework before pouring concrete. It is not necessary to tie up steel bars, this shortens the construction period and improves efficiency. For structures that are not suitable for supporting formwork, the formwork can be suspended on the steel trusses, and the construction loads can be borne by the steel trusses, so as to indicate self-bearing during the construction stage. Due to the fact that the square steel tube truss concrete composite beam have higher rigidity and bearing capacity, if they are used as precast members, they can minimize the section size and reduce transport and lifting costs. Recent researches on this kind of composite beams have not covered pattern failures and the main factors affecting the flexural capacity of normal sections. Therefore, it is of great engineering significance to investigate the flexural performance of the square steel tube truss concrete beams and propose calculation methods of the flexural capacity of this kind of beam. 
Recently, steel trusses are widely utilized in long-span buildings and bridge structures due to their light self-weight and high bearing capacity [3-5]. On the other hand, if steel trusses are directly used as frame beams, the following drawbacks can be encountered: low section stiffness, large appearance size, poor durability, and lower fire resistance performance. Moreover, in cast-in-place concrete structures, the connection details of steel trusses with floor slab and concrete columns are also complex. Therefore, steel trusses are often buried into concrete beams to form flexural composite members, which can overcome the above problems. To this point, reports on concrete beams with embedded steel trusses mainly focus on bearing capacity, stiffness, and crack width. Zheng et al. $[6,7]$ and Zhang et al. [8] studied the flexural and seismic behaviour of prestressed steel tube truss concrete composite beams with grouted chords, and the calculation formulae for bearing capacity and crack width of normal sections were put forward. Furthermore, Deng et al. [9] investigated the flexural behaviour of steel truss reinforced concrete beams with rectangular and $\mathrm{T}$-shaped sections; Wang and $\mathrm{Mu}$ [10] also studied the cross-sectional strain distribution, deformation, stress increment of prestressed tendons, and crack distribution for unbonded prestressed lattice-type steel-reinforced concrete beams by tests; Arafa et al. [11] then analyzed the shear performance of concrete beams with embedded angle steel truss under different shear span ratios by the finite element model. Nevertheless, Colajanni et al. [12] investigated the failure modes and stress transfer mechanism of steel-concrete trussed beams. In addition, Chen et al. [13] proposed a theoretical calculating model for composite box girders with corrugated steel webs and steel trusses. Relevant researches indicate that the load-carrying capacity and stiffness of concrete beams could be improved by substituting ordinary steel bars skeleton with steel trusses. However, the above-mentioned research studies do not include test and numerical studies of the square steel tube truss concrete beams with grouted chords proposed in this paper. The finite element analysis (FEA) method was used to curb issues of high cost, few parameter variables, and insufficient stress state investigation.
Therefore, to study the flexural behaviour of square steel tube truss concrete beams with grouted chords, the FEA models for this type of composite beams were established by soft ABAQUS. The predicted vertical load-deflection curves failure patterns and steel tube strain distribution were compared with the test results. The parameter analysis was also carried out. Finally, the calculation approach of flexural capacity for square steel tubular truss beams with grouted chords was established based on the tested and simulated results. This provided a basis for the design of such composite beams.

\section{Establishment of Finite Element Analysis Models}

2.1. Constitutive Relation of Materials. Due to the monotonic loading in tests, concrete is often simulated without considering the influence of damage, thus the plastic aspect of the damage plastic (DP) model provided by ABAQUS is adopted [14]. The stress-strain $(\sigma-\varepsilon)$ relationship of concrete subjected to uniaxial tension and compression assumes the two-parameter model [15] recommended in code for design of concrete structures (GB20010-2010), as shown in Figure 1(a) and expressed by equation (1), where $f_{c}, \varepsilon_{0}, f_{t}$, and $\varepsilon_{t 0}$ are the axial compressive strength, peak compressive strain, axial tensile strength, and corresponding strain of concrete, respectively; $\alpha_{a}$ and $\alpha_{d}$ are the coefficients parameters of ascending and descending stages for the compressive curve; $\alpha_{t}$ is the factor of descending segment for tensile curve. In FEA models, the shear expansion angle $\psi$ of concrete takes $30^{\circ}$, the eccentricity $e$ is equal to 0.1 , the ultimate strength ratio $\sigma_{b 0} / \sigma_{c 0}$ between biaxial and uniaxial compression for the concrete assumes 1.16, and the strength ratio of concrete under equal biaxial compression to triaxial compression $K_{c}$ takes $2 / 3$. For the purpose of convergency, the viscosity coefficient $\mu=0.001$ is adopted in the calculation. The steel tube stress-strain $\left(\sigma_{a}-\varepsilon_{a}\right)$ curve for the upper and lower chords, web members, and connecting rods of the trusses adopt the ideal elastic-plastic model, as shown in Figure 1(b), where $f_{a}, \varepsilon_{\text {ya }}$, and $E_{a}$ are the yield strength, yield strain, and modulus of elasticity for steel tubes.

$$
\sigma= \begin{cases}f_{c} \cdot\left[\alpha_{a}\left(\frac{\varepsilon}{\varepsilon_{0}}\right)+\left(3-2 \alpha_{a}\right) \cdot\left(\frac{\varepsilon}{\varepsilon_{0}}\right)^{2}+\left(\alpha_{a}-2\right) \cdot\left(\frac{\varepsilon}{\varepsilon_{0}}\right)^{3}\right], & 0 \leq \varepsilon \leq \varepsilon_{0}, \\ f_{c} \cdot \frac{\left(\varepsilon / \varepsilon_{0}\right)}{\alpha_{d}\left(\varepsilon / \varepsilon_{0}\right)^{2}+\left(\varepsilon / \varepsilon_{0}\right)}, & \varepsilon>\varepsilon_{0}, \\ f_{t} \cdot\left[1.2\left(\frac{\varepsilon}{\varepsilon_{0}}\right)-0.2\left(\frac{\varepsilon}{\varepsilon_{0}}\right)^{6}\right], & \varepsilon_{t 0}<\varepsilon<0, \\ f_{t} \cdot \frac{\left(\varepsilon / \varepsilon_{t}\right)}{\alpha_{t}\left(\varepsilon / \varepsilon_{t 0}-1\right)^{1.7}+\left(\varepsilon / \varepsilon_{t 0}\right) \sigma}, & \varepsilon<\varepsilon_{t 0} .\end{cases}
$$




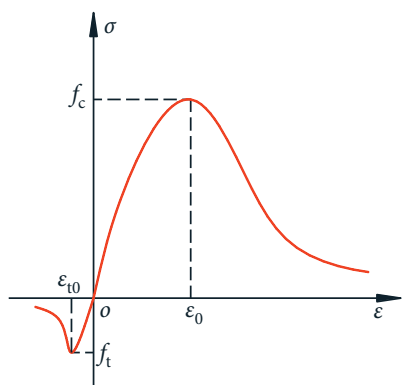

(a)

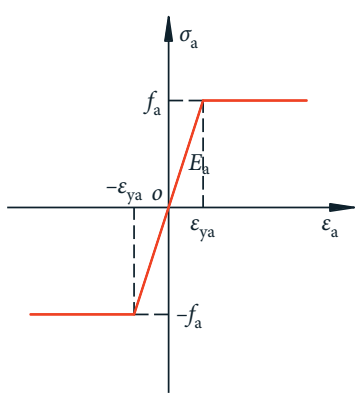

(b)

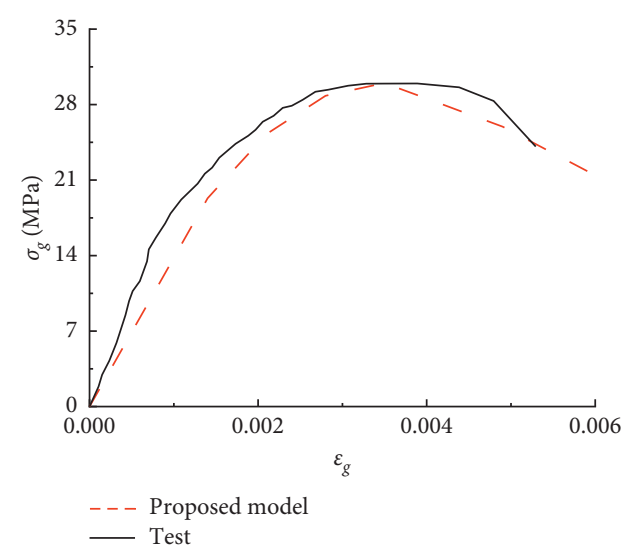

(c)

FIgure 1: Constitutive relationship of materials. (a) Concrete. (b) Steel tube. (c) Grouting material.

In order to prevent the chords of steel tube trusses from cave-in failure, cement paste used as grouting material was poured into both the upper and lower chords. Due to the lack of coarse aggregate, the peak compressive strain of hardened grouting material is larger than that of ordinary concrete, which is in the range of 0.003 to 0.004 [16]. At present, there is almost no research on the constitutive relation of hardened cement paste, so the uniaxial compression two-parameter model for concrete offered in GB20010-2010 is used as a reference. Thus, the stress-strain $\left(\sigma_{g}-\varepsilon_{g}\right)$ relation of grouting material subjected to uniaxial compression is proposed in this paper, as shown in equation (2), in which $f_{g}$ and $\varepsilon_{g 0}$ are the axial compressive strength and corresponding strain for the hardened cement paste, and value of $\varepsilon_{g 0}$ takes 0.0035 . The comparison between the compressive stress-strain $\left(\sigma_{g}-\varepsilon_{g}\right)$ relation and the test results of grouting material is illustrated in Figure 1(c), which reveals that the proposed model is essentially identical with tests and it can be used for FEA models. The constitutive relationship of grouting material subjected to tension is the same as that of ordinary concrete with the same strength.

$$
\sigma_{g}= \begin{cases}f_{g} \cdot\left[\alpha_{a}\left(\frac{\varepsilon_{g}}{\varepsilon_{g 0}}\right)+\left(3-2 \alpha_{a}\right) \cdot\left(\frac{\varepsilon_{g}}{\varepsilon_{g 0}}\right)^{2}+\left(\alpha_{a}-2\right) \cdot\left(\frac{\varepsilon_{g}}{\varepsilon_{g 0}}\right)^{3}\right], & 0 \leq \varepsilon_{g} \leq \varepsilon_{g 0}, \\ f_{g} \cdot \frac{\left(\varepsilon_{g} / \varepsilon_{g 0}\right)}{\alpha_{d}\left(\varepsilon_{g} / \varepsilon_{g 0}\right)^{2}+\left(\varepsilon_{g} / \varepsilon_{g 0}\right)}, & \varepsilon_{g}>\varepsilon_{g 0} .\end{cases}
$$

2.2. Finite Element Model and Boundary Conditions. The typical FEA model of square steel tube truss concrete beam established by soft ABAQUS is illustrated in Figure 2. During modelling, three kinds of parts, square steel tube trusses shown in Figure 2(a), concrete beam shown in Figure 2(b), which involves grouting materials, and rigid plates for loading and support were established, respectively. Since the web members and linking rods of the square steel tube truss were not grouted, the corresponding solid in the concrete beam part was hollowed out by cutting commands; for the grouting material of the upper and lower chord, the corresponding solids in the concrete beam part were cut off and retained. Tetrahedral element C3D10 with higher geometric adaptability is used for concrete and grouting materials, the shell element S4R is used for square steel tubes, and solid element C3D8R is used for rigid plates. The reasonable sizes of the element division can improve the computational efficiency and precision of the FEA models.
Throughout the analysis, the FEA results are more consistent with the experimental results when the overall grid size is $15 \mathrm{~mm}$ and $50 \mathrm{~mm}$ for trusses and concrete surface, respectively, and adaptive grid technique is applied for concrete internal grids. To simplify the analysis in FEA modelling, the slip between the steel trusses part and the concrete beam part is neglected, and the embed technique is adopted to carry out coupling.

The two ends of the FEA model of the composite beam are simply supported, and four-point loading is adopted. In order to prevent stress concentration, the four rigid plates are separately set at two supports and two loading points on the composite beam, and tie technology is applied to bind the rigid plates and concrete surfaces, as shown in Figure 2(c). Here, the value of symmetrical vertical concentrated load takes $P / 2$, and $U_{x}, U_{y}$, and $U_{z}$ are the displacements of the supports in the direction of global coordinates $X, Y$, and $Z$, respectively. For the simply 


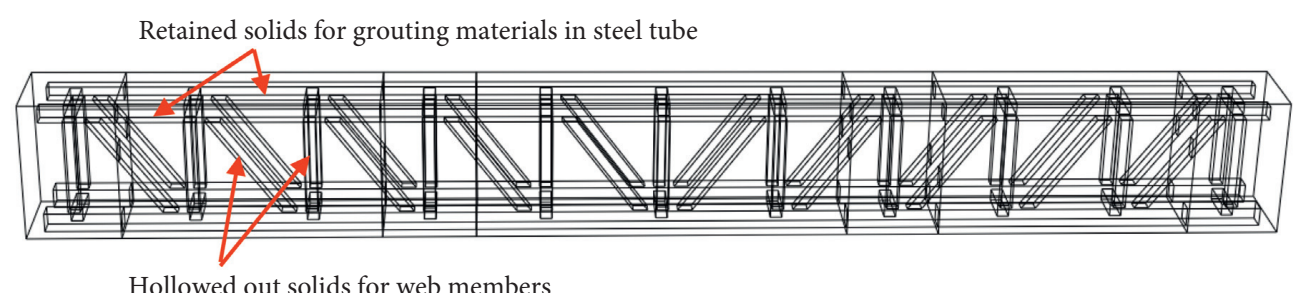

(a)

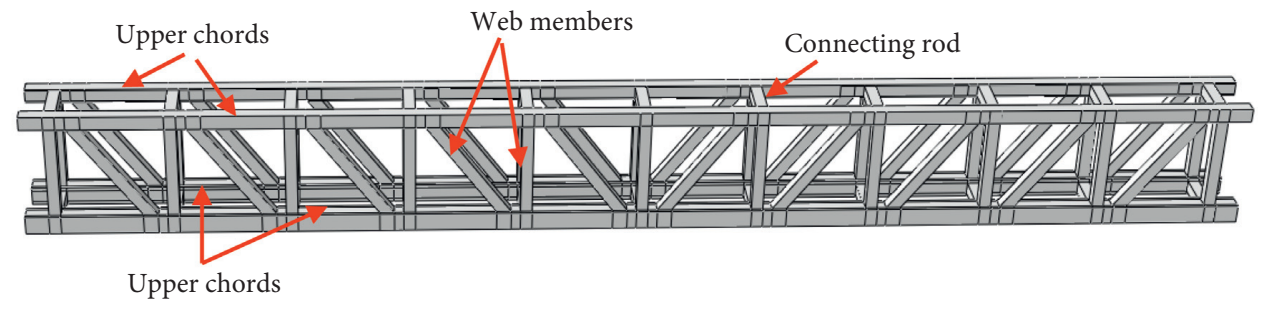

(b)

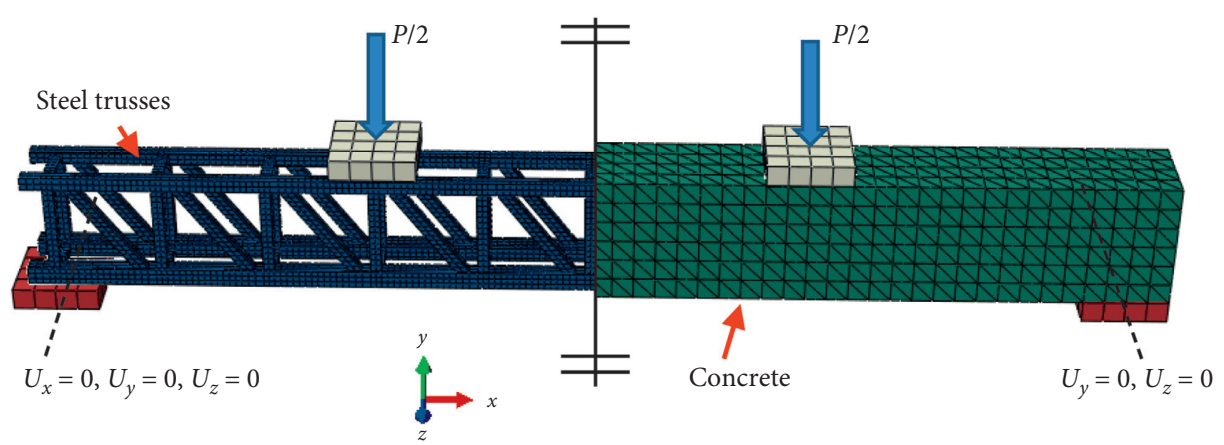

(c)

Figure 2: Finite element analysis model. (a) Part of concrete beam. (b) Part of steel tube truss. (c) Loading and constraints.

supported beam, fixed hinge support is set at the left end $\left(U_{x}=U_{y}=U_{z}=0\right)$ and sliding hinge support is set at the right end $\left(U_{x}=U_{y}=0\right)$, and the vertical loads are placed by displacement control method.

\section{Verification of the Numerical Model}

3.1. The Experiments. Figure 3 gives the layout of reinforcement and strain gauges for square steel tube truss concrete beams with grouted chords, and the specimens were numbered as B-1 B-5. The length of beam specimens is $2700 \mathrm{~mm}$, the calculated span is $2500 \mathrm{~mm}$, the cross-sectional size is $200 \mathrm{~mm} \times 300 \mathrm{~mm}$, and the concrete strength grade is C40. The measured average compressive strength of concrete cube $f_{\mathrm{cu}}$ is $44.8 \mathrm{MPa}$, axial compressive strength $f_{c}$ is $34.05 \mathrm{MPa}$, axial tensile strength $f_{t}$ is $3.2 \mathrm{MPa}$, and modulus of elasticity $E_{\mathrm{c}}$ is $3.36 \times 10^{4} \mathrm{MPa}$ [17]. Grouting material was made by P.O 42.5 ordinary silicate cement, UEA expansive agent, FDN superplasticizer, and tap-water. The measured mean axial compressive strength $f_{g}$ of grouting material cube after 28-days standard curing is $36.3 \mathrm{MPa}$. The cross-sectional sizes of connecting rods and web members for all embedded steel trusses take $25 \mathrm{~mm} \times 25 \mathrm{~mm} \times 2 \mathrm{~mm}$, and the yield strength $f_{a}$ is $360 \mathrm{MPa}$. The yield strength $f_{a}$ for chord tubes with crosssectional sizes of $30 \mathrm{~mm} \times 30 \mathrm{~mm} \times 2 \mathrm{~mm}, \quad 30 \times 30 \mathrm{~mm}$ $\times 3 \mathrm{~mm}, \quad 40 \mathrm{~mm} \times 40 \mathrm{~mm} \times 2 \mathrm{~mm}$, and $\quad 40 \mathrm{~mm} \times 40 \mathrm{~mm}$ $\times 3 \mathrm{~mm}$ is $297 \mathrm{MPa}, \quad 345 \mathrm{MPa}, 355 \mathrm{MPa}$, and $312 \mathrm{MPa}$, respectively.

In the tests, four-point symmetrical loading was adopted by distributive girder as shown in Figure 4. The total vertical load $P$ is measured by a load sensor, and the deflection $\Delta$ at midspan is calculated according to the data of dial indicators at midspan and supports. Strain gauges are fixed on the upper and lower chords of steel tube trusses and concrete in the pure bending segment. The test results showed that all the five beam specimens showed flexural failure, with the concrete in compression zone crushing after the lower chords reaching full tensile yielding, while the upper chords not yielding completely.

3.2. Load-Deflection Curves. Figure 5 shows the comparison of load-deflection $(P-\Delta)$ curves obtained from beam specimens and FEA models. Table 1 lists the simulated and test crack stiffnesses $\left(E_{\mathrm{cr}}^{s}\right.$ and $\left.E_{\mathrm{cr}}^{t}\right)$ and ultimate loads $\left(P_{u}^{s}\right.$ and $\left.P_{u}^{t}\right)$. It was found that the crack loads calculated by the FEA models are close to the test results, but the crack displacement calculated was smaller than that of the measured values, which caused crack stiffnesses for FEA models which were greater than that of tests. With the increase of vertical loads, the predicted stiffnesses after cracking were also larger than measured results since the yield of steel tubes of lower 


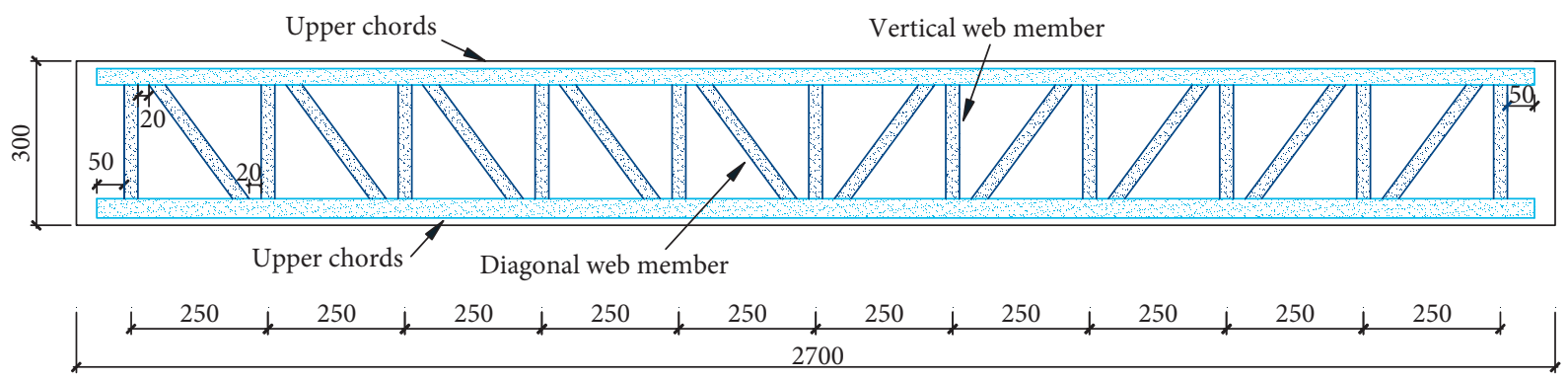

(a)
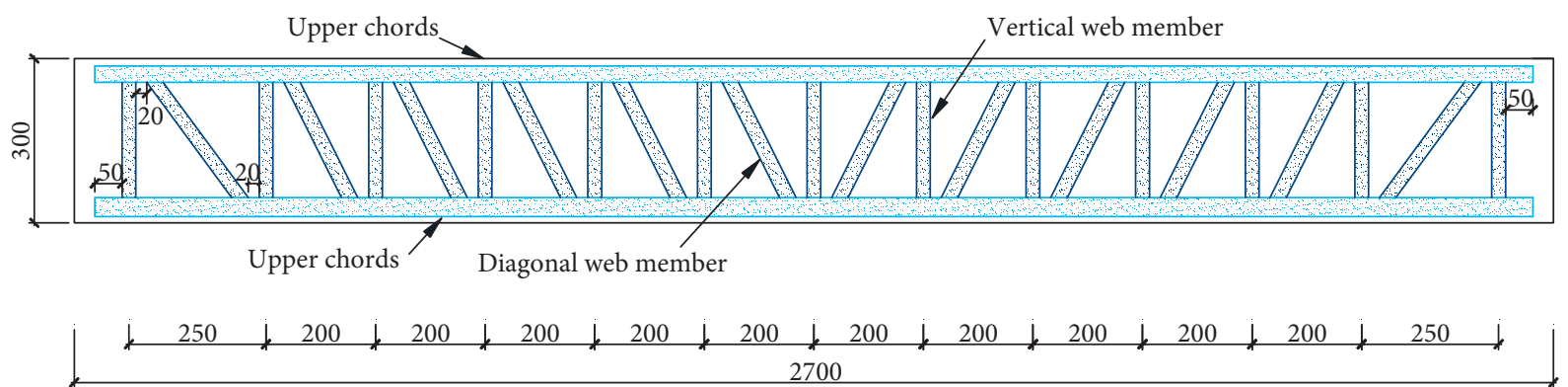

(b)
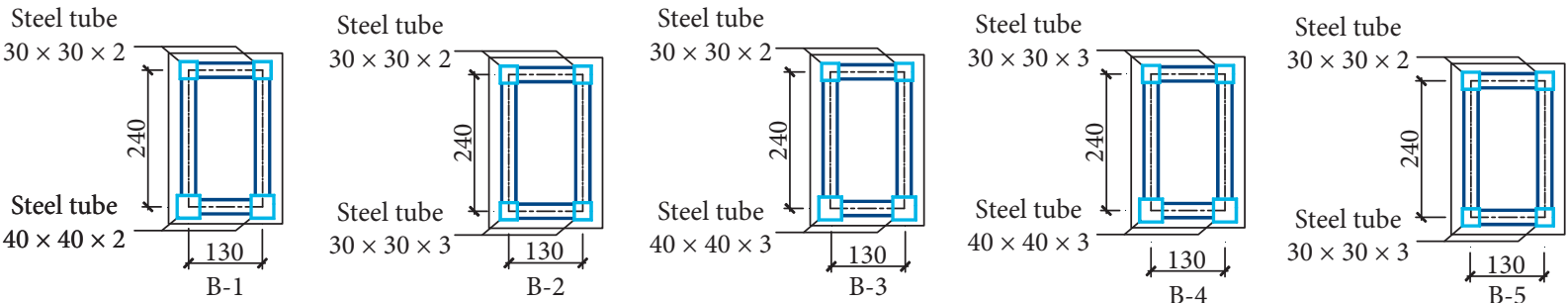

(c)

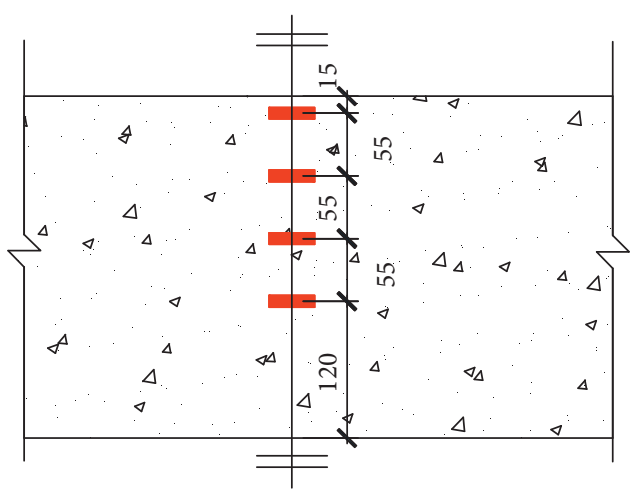

(d)

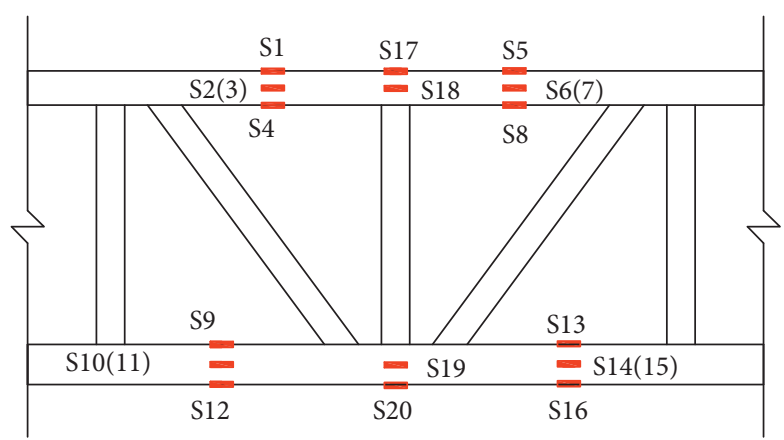

(e)

FIGURE 3: Detailed configurations of embedded square steel tube trusses and gauges distribution (unit: mm). (a) Elevation view for beam specimens B-1, B-2, B-3, and B-4. (b) Elevation view of beam specimen B-5. (c) Cross-section details. (d) Strain gauges on concrete. (e) Strain gauges on steel truss.

chords is a gradual process, and there is no obvious yield point on the calculated and test curves, which is obviously different from the yield case of the ordinary reinforced concrete beam; when the failure is achieved, the predicted ultimate loads' $P_{u}^{s}$ are close to the test values $P_{u}^{t}$, with about $5 \%$.

Generally, the calculated curves and ultimate bearing capacities are similar to the tested ones. The reason for the increase of initial stiffness and post-cracking stiffness mentioned above could be explained as follows: (1) the concrete elements in the FEA models are continuous and there is no crack development, thus the impact of cracking cannot be accurately considered in the whole loading process. (2) DP model is adopted for concrete without considering the impact of the damage. (3) The slip between steel trusses and concrete are considered in the FEA models. 


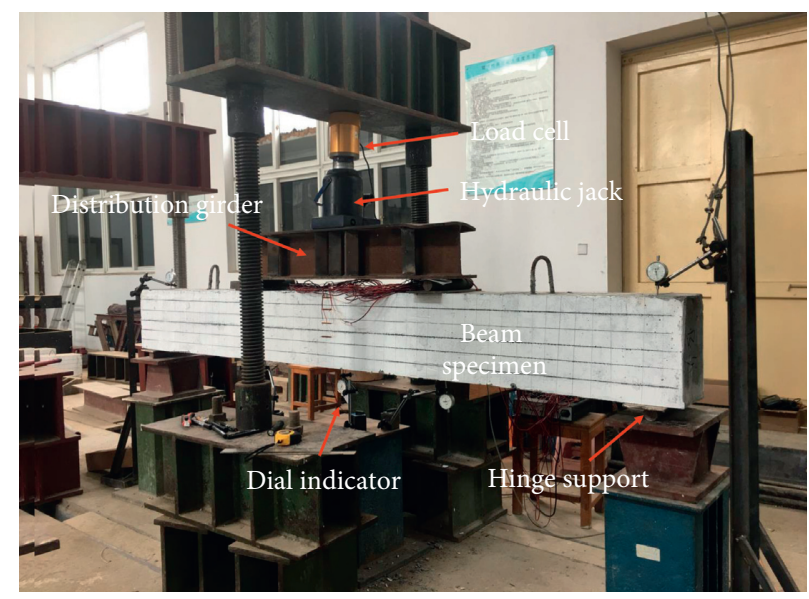

Figure 4: Loading apparatus.
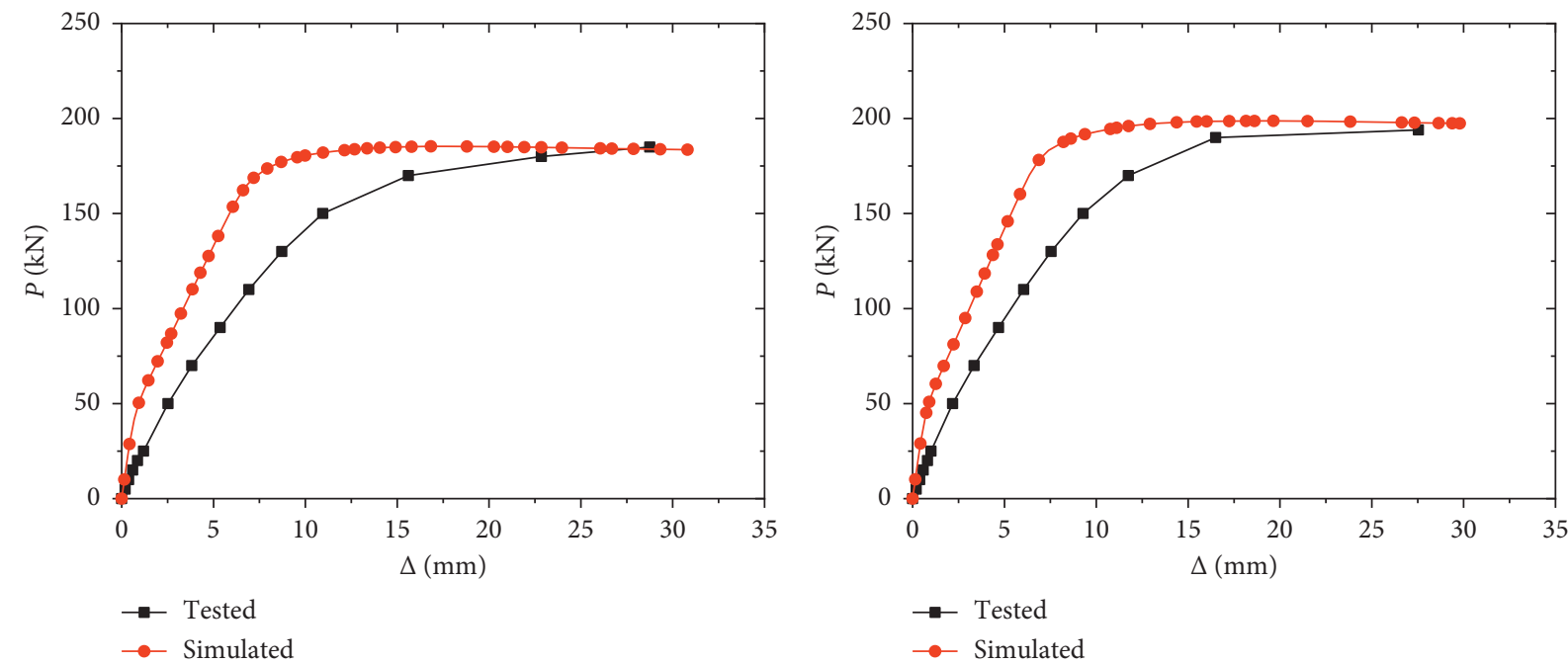

(a)

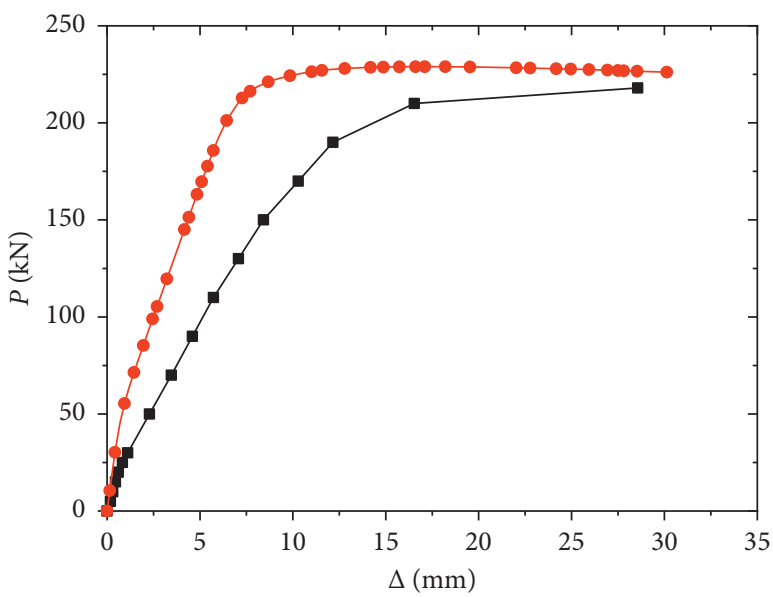

(b)

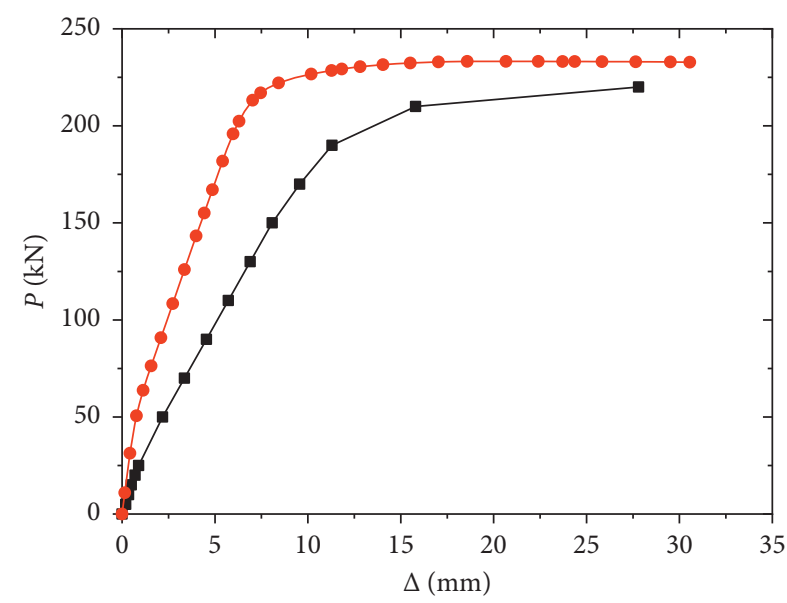

- Tested

$\rightarrow$ Tested

$\rightarrow$ Simulated

(c)

(d)

Figure 5: Continued. 


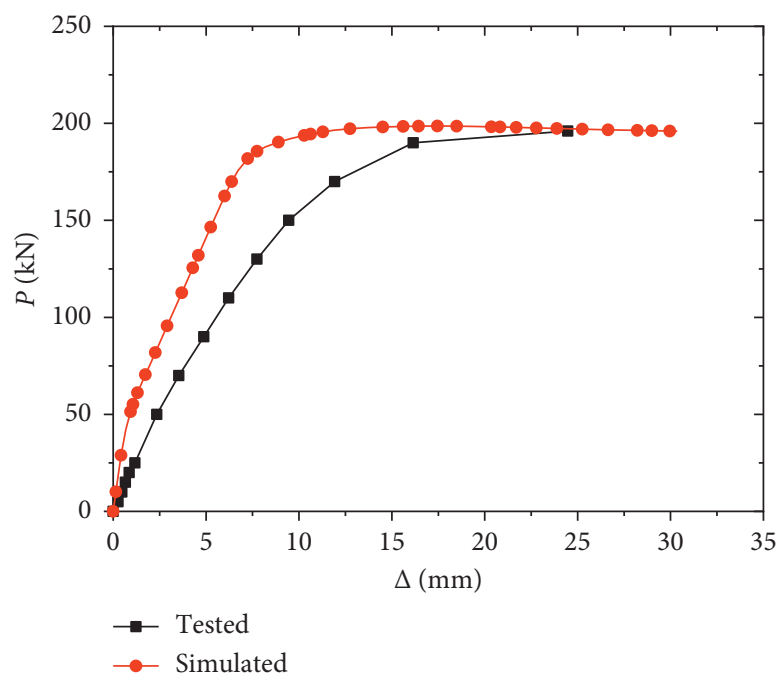

(e)

FIGURE 5: Load-deflection curves of tests and FEA models. (a) B-1. (b) B-2. (c) B-3. (d) B-4. (e) B-5.

TABle 1: Comparison of crack and ultimate loads between simulation and tests.

\begin{tabular}{lccccc}
\hline $\begin{array}{l}\text { Beam } \\
\text { number }\end{array}$ & $\begin{array}{c}E_{\mathrm{cr}}^{s} \\
(\mathrm{kN} / \mathrm{mm})\end{array}$ & $\begin{array}{c}E_{\mathrm{cr}}^{t} \\
(\mathrm{kN} / \mathrm{mm})\end{array}$ & $P_{u}^{s}(\mathrm{kN})$ & $P_{u}^{t}(\mathrm{kN})$ & $P_{u}^{t} / P_{u}^{s}$ \\
\hline B-1 & 67.3 & 21.0 & 185.4 & 185.0 & 1.00 \\
B-2 & 68.0 & 25.0 & 198.7 & 194.0 & 0.98 \\
B-3 & 70.8 & 27.0 & 228.9 & 218.0 & 0.95 \\
B-4 & 73.4 & 28.1 & 233.3 & 220.0 & 0.94 \\
B-5 & 67.8 & 21.4 & 198.6 & 196.0 & 0.99 \\
\hline
\end{tabular}

3.3. Comparison of Failure Modes. The ultimate compressive strain $\varepsilon_{\text {cu }}$ of concrete is often taken as 0.0033 . When the compressive strain (denoted by E11) in the length direction of concrete exceeds $\varepsilon_{\mathrm{cu}}$, it indicates that concrete is crushed. The yield of steel tube trusses could be observed by the plastic strains (represented as PE11). When the plastic strain PE11 of the upper and lower chords of the steel tube trusses in the axial direction of members is greater than zero, it indicated that the chords reached yielding. Taking typical beam specimen B-1 as example, the strain of concrete and plastic strain of steel tube trusses for the FEA model at failure were obtained, as shown in Figures 6(a) and 6(b). As shown in Figure 6(a), the compressive strain E11 of concrete in the upper part of the pure bending segment of the FEA beam model was far from the ultimate compressive strain of 0.0033 up to 0.01 , and the depth of the compression zone was about $30 \mathrm{~mm}$, which indicates that the concrete had been crushed and the simulated failure was basically consistent with the experimental observation shown in Figure 6(c). It can be concluded from Figure 6(b) that the lower chords of steel tube trusses have yielded in the whole pure bending segment, with a maximum yield strain of 0.0359 , which indicates that the FEA results can clearly reflect the observation of failure.
3.4. Strain Variation of Steel Tubes. The test and calculated curves of vertical load $(P)$ and steel tube strain $(\varepsilon)$ are compared in Figure 7, where strain gauges $S 1$ and $S 9$ were fixed on the upper and lower chords. From initial loading to failure, the vertical load-strain $(P-\varepsilon)$ curves corresponding to the measuring point $S 1$ calculated by the FEA method are matching with the measured results, in which the steel tube strains of S1 vary linearly with the increase of vertical loads, and the strains yield slightly at the peak load for some specimens. For the measuring point S2, there is a certain gap between the simulated and tested load-strain curves, which is mainly reflected by the fact that the slope of the calculated curves is larger than that of the tested ones before yielding of the steel tubes; but when the loads reached the peak values, the calculated strains of $S 1$ are greater than the yield strain. The reason for the above distinction could be explained by the DP model of the concrete which was adopted whereby the elements were continuous without considering cracks.

\section{Parameter Analysis}

Studies on flexural capacity and parameter analysis on vertical load-deflection curves by FEA models were conducted. The primary analysis parameters involved the concrete strength grade $f_{\text {cuk }}$, steel ratio of upper and lower chords $\left(\rho_{a}^{\prime}\right.$ and $\left.\rho_{a}\right)$, and the spacing $(s)$ between adjacent truss joints. Table 2 gives basic information. In the parameter analysis, the FEA models were taken as a simply supported beam with the length of $2700 \mathrm{~mm}$, the calculated span of $2500 \mathrm{~mm}$, and the cross-section size of $200 \mathrm{~mm} \times 300 \mathrm{~mm}$. The dimensions of the web member and connecting rods for encased steel trusses were both $25 \mathrm{~mm} \times 25 \mathrm{~mm} \times 2 \mathrm{~mm}$. The steel tube yield strength is $f_{y}=235 \mathrm{~N} / \mathrm{mm}^{2}$, and the concrete strength is taken as the standard value. In addition, no shear failure occurred in these FEA models. 

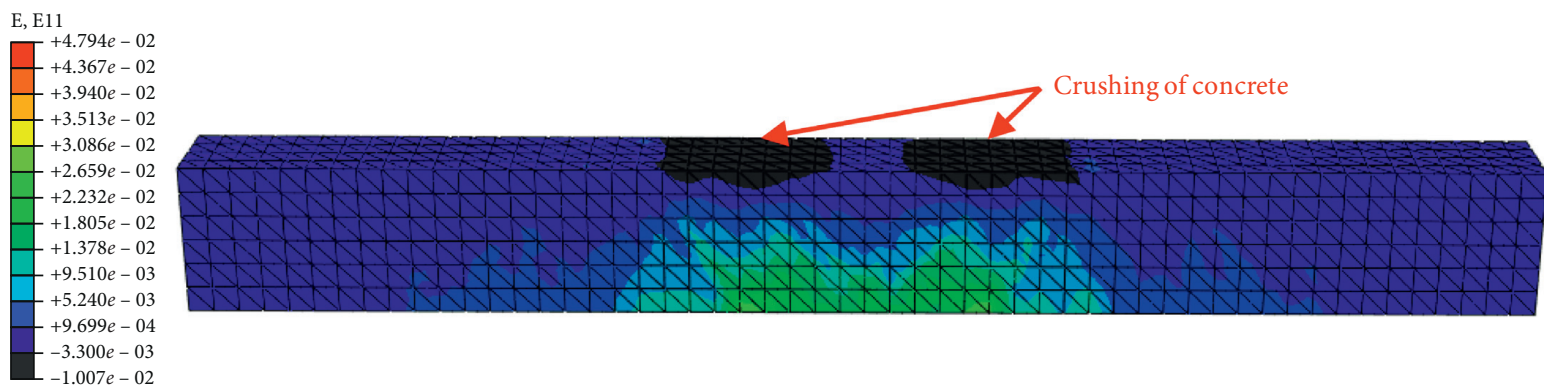

(a)
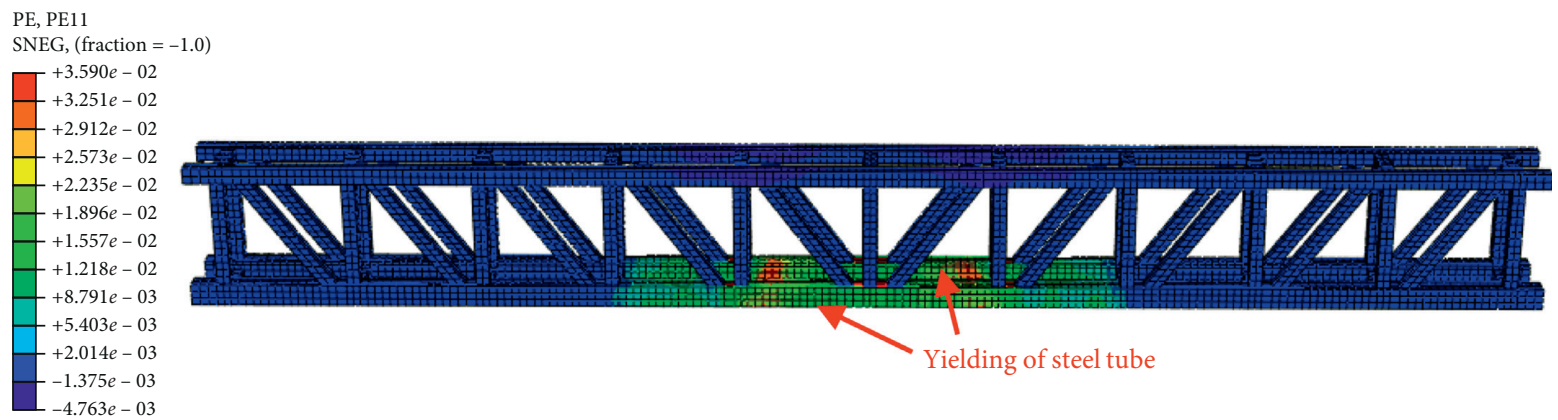

(b)

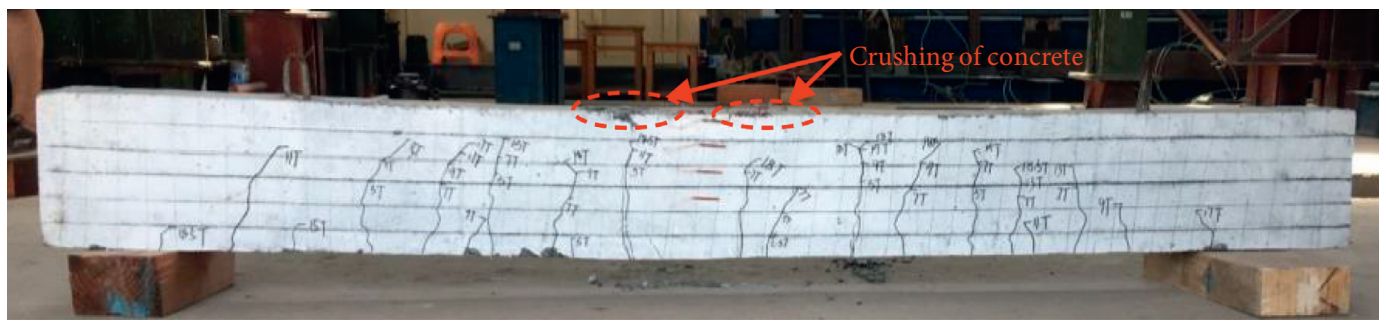

(c)

FIGURE 6: Comparison of failure modes. (a) Crushing of concrete for FEA model. (b) Yielding of steel trusses for FEA model. (c) Failure mode of beam specimens.

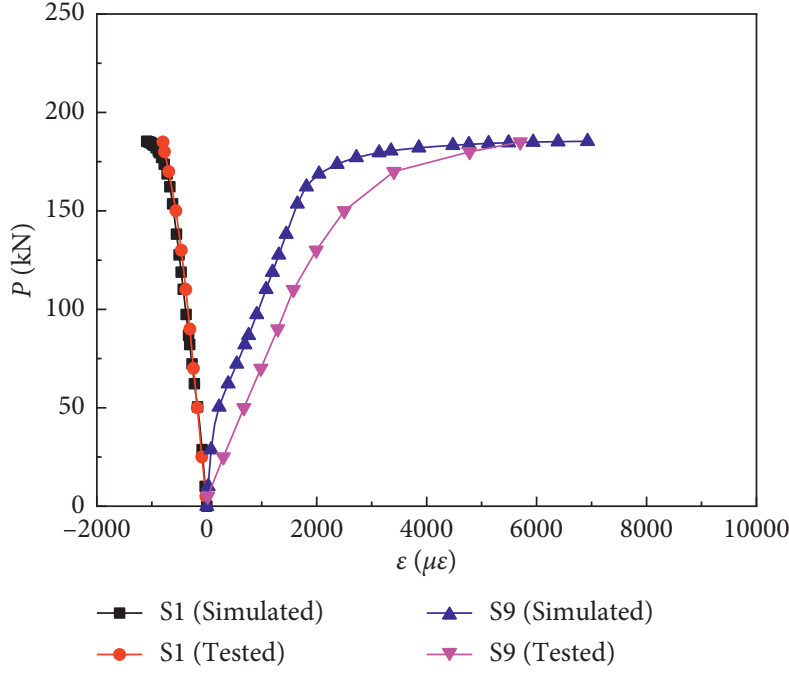

(a)

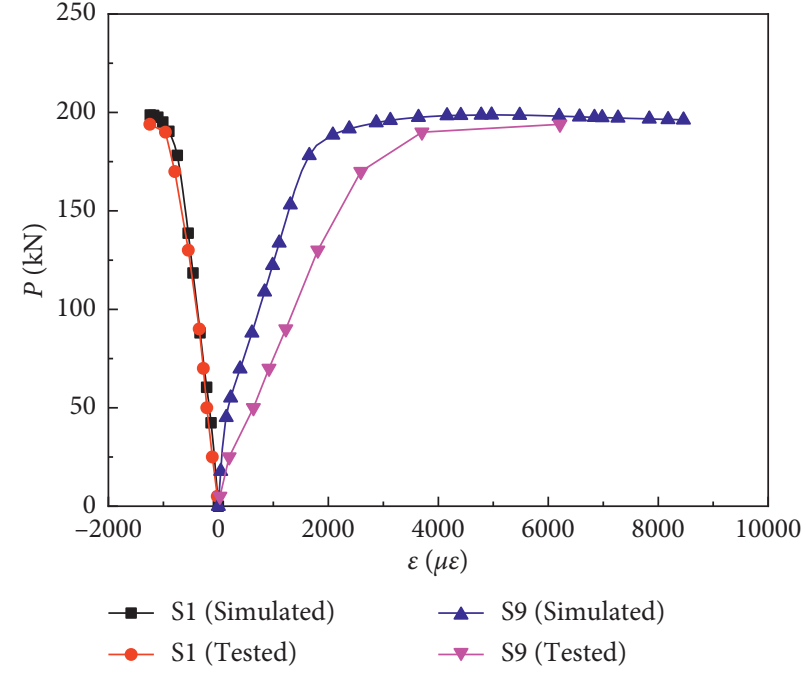

(b)

Figure 7: Continued. 


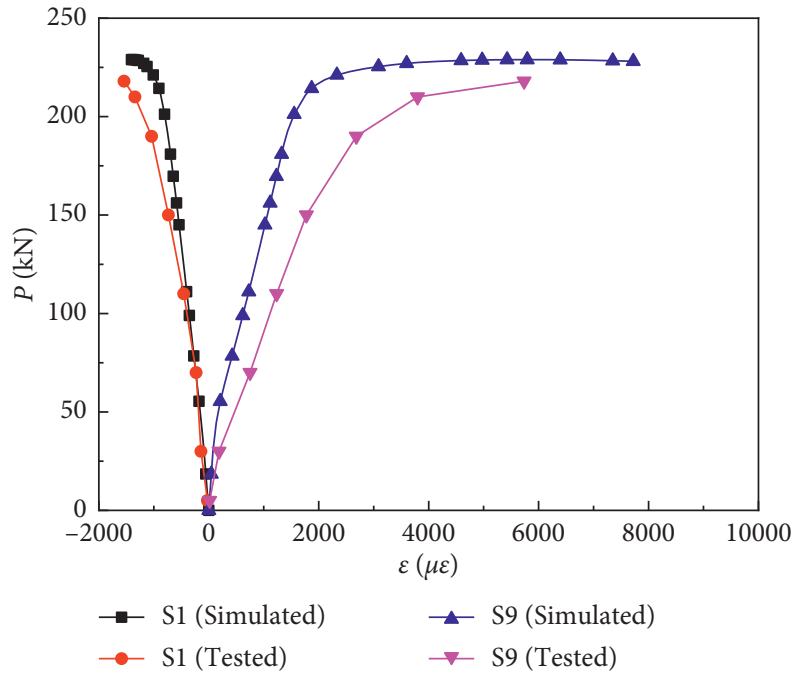

(c)

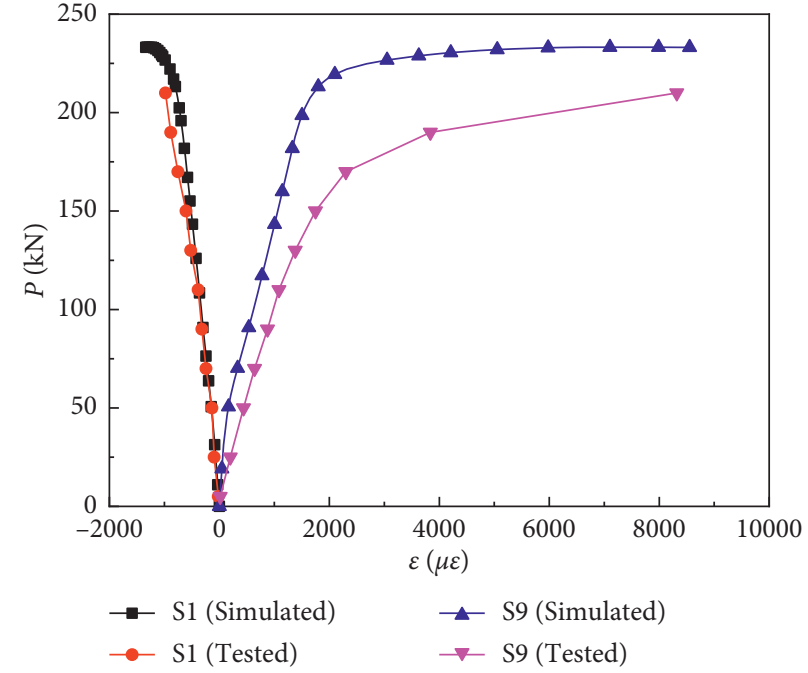

(d)

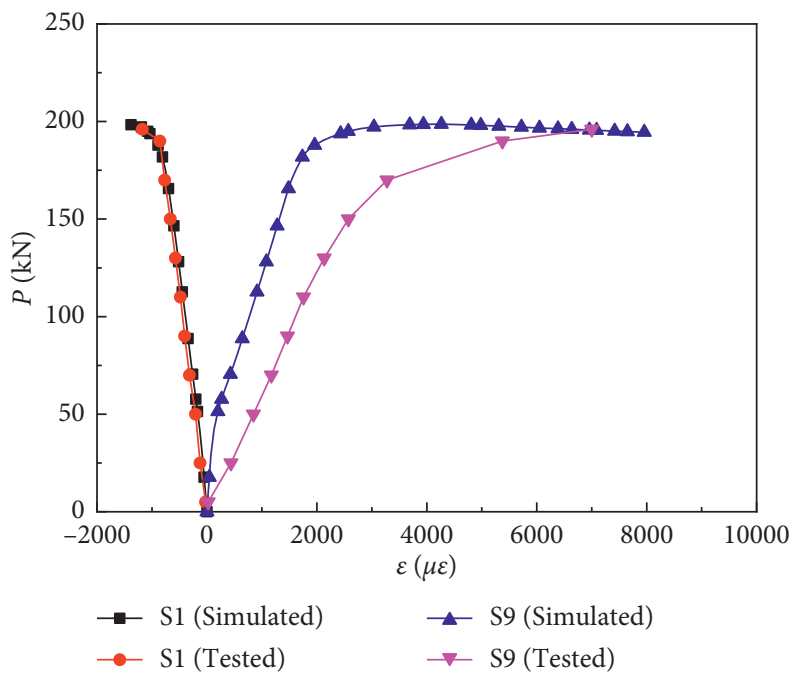

(e)

Figure 7: Vertical load-strain curve of steel tube. (a) B-1. (b) B-2. (c) B-3. (d) B-4. (e) B-5.

TABle 2: Parameters of FEA models.

\begin{tabular}{lcc}
\hline Analytical parameters & Range of parameters & Description \\
\hline Concrete strength grade & C30; C45; C50 & $f_{\text {cuk }}: 30 \mathrm{~N} / \mathrm{mm}^{2}, 40 \mathrm{~N} / \mathrm{mm}^{2}$, and $^{2} 50 \mathrm{~N} / \mathrm{mm}^{2}$ \\
Steel ratio of upper chords $\left(\rho_{a}^{\prime}\right)$ & $0.43 \% ; 0.63 \% ; 0.83 \%$ & Area: $232 \mathrm{~mm}^{2}, 342 \mathrm{~mm}^{2}$, and $_{4} 448 \mathrm{~mm}^{2}$ \\
Steel ratio of lower chords $\left(\rho_{a}\right)$ & $1.64 \% ; 2.13 \% ; 2.56 \%$ & Area: $888 \mathrm{~mm}^{2} ; 1152 \mathrm{~mm}^{2} ; 1400 \mathrm{~mm}^{2}$ \\
Spacing of truss joint $(s)$ & $200 \mathrm{~mm} ; 250 \mathrm{~mm} ; 500 \mathrm{~mm}$ & - \\
\hline
\end{tabular}

4.1. Concrete Strength. Figure 8(a) gives the vertical loaddeflection $(P-\Delta)$ curve of square steel tube truss concrete beams with grouted chords under different concrete strength grades. When the concrete strength grades are C30, C40, and C50, respectively, the initial stiffnesses for $P-\Delta$ curves are basically the same, and the stiffnesses after cracking and yielding increased slightly. The peak values of vertical loads at failure are $135.0 \mathrm{kN}, 137.6 \mathrm{kN}$, and $139.8 \mathrm{kN}$, respectively, with an increment of $1.9 \%$ and $3.6 \%$. This indicates that improving the concrete strength could enhance the vertical load of members to a certain extent, however, the increments were very small.
4.2. Steel Ratio of Upper Chords. The vertical load-deflection $(P-\Delta)$ curves for square steel tube truss concrete beams with different steel ratio of upper chords are compared in Figure $8(\mathrm{~b})$. With an increment of steel ratio, the crosssectional area $A_{a}^{\prime}$ is in the order of $232 \mathrm{~mm}^{2}, 342 \mathrm{~mm}^{2}$, and $448 \mathrm{~mm}^{2}$, and an increment of $47.4 \%$ and $93.1 \%$. The curve shapes are essentially similar, and the stiffnesses increased slightly after cracking. The vertical load peak at failure corresponding to the cross-sectional area of the different upper chord steel tubes is $133.4 \mathrm{kN}, 134.4 \mathrm{kN}$, and $135.0 \mathrm{kN}$, respectively, and the vertical peak loads increase by $0.7 \%$ and 


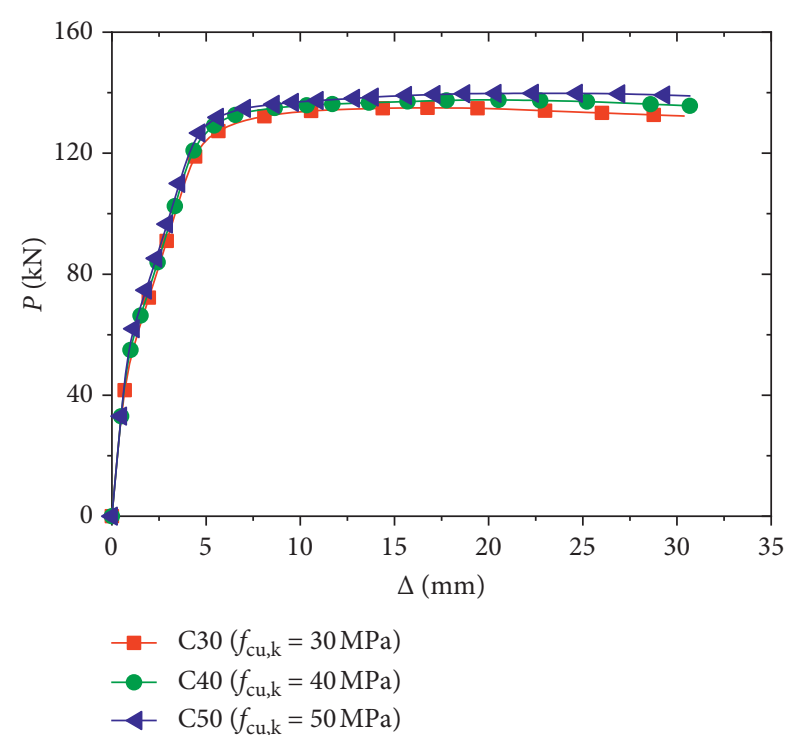

(a)

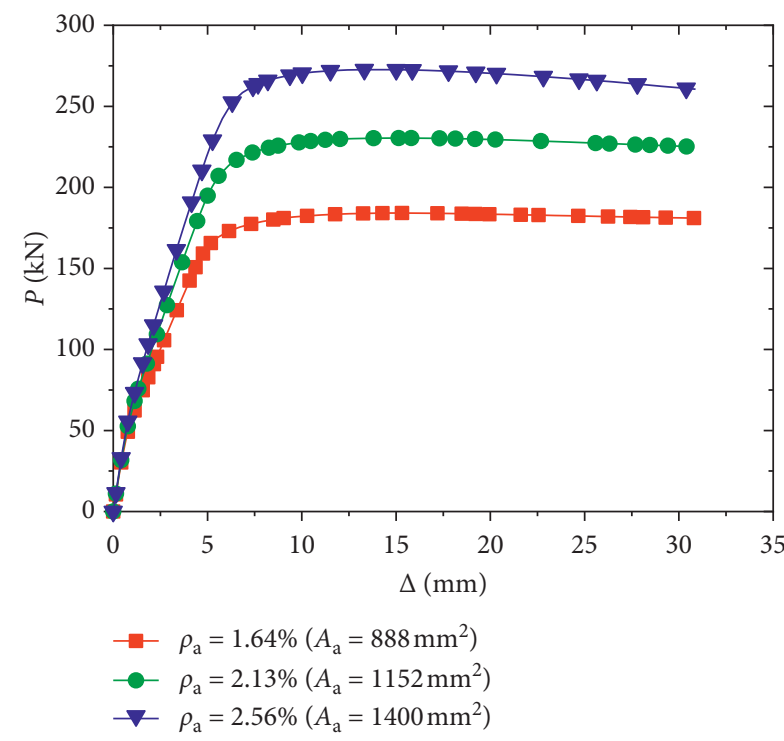

(c)

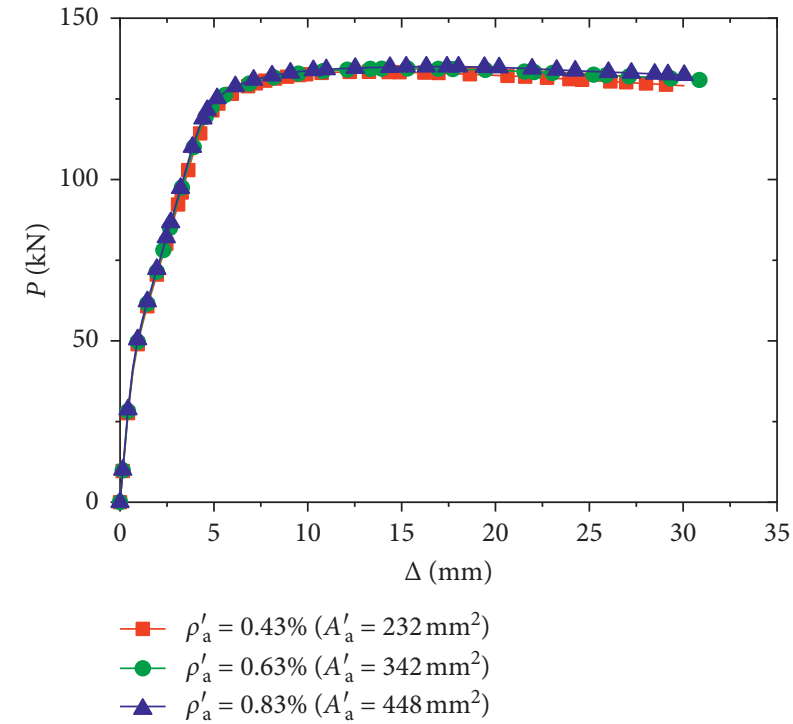

(b)

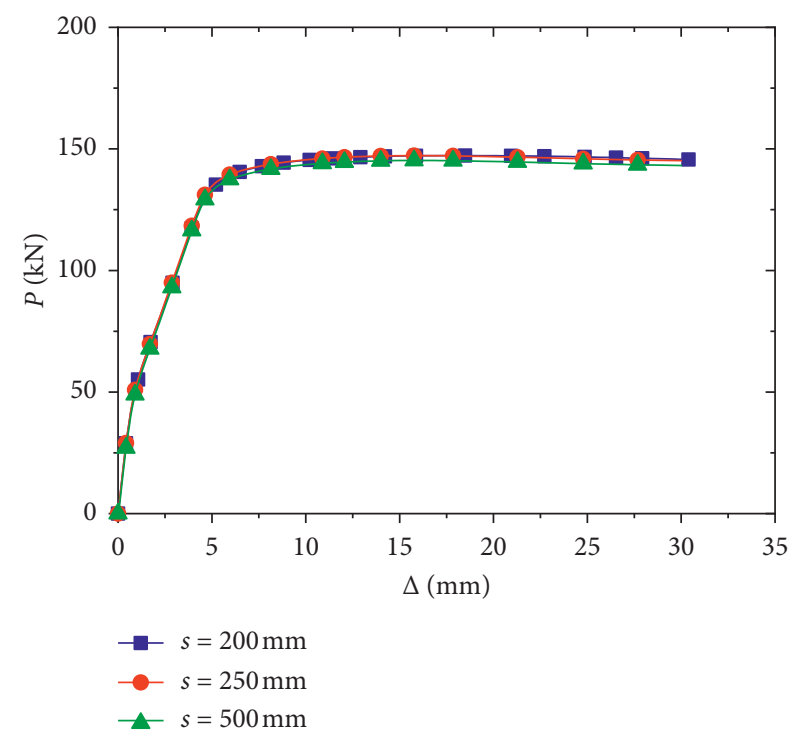

(d)

FiguRE 8: Influence of different parameters on load-deflection curves. (a) Concrete strength grade. (b) Steel ratio of steel tube of upper chords. (c) Steel ratio of steel tube of lower chords. (d) Truss joint spacing.

$1.2 \%$, respectively. It can be seen that increasing the sectional area of the upper chords has little influence on enhancing the vertical bearing capacity. Due to the structural requirements of upper chords of steel trusses, the sectional area is generally large, and they cannot reach full yielding at peak loads.

4.3. Steel Ratio of Lower Chords. Figure 8(c) shows the influence of the steel ratio of the lower chords on the vertical load-deflection $(P-\Delta)$ for the composite beams. It indicates that the vertical peak load and yield stiffness of the composite beam raised with an increase of steel ratio of the lower chords. When the steel ratio is $1.64 \%, 2.13 \%$, and $2.56 \%$, with cross-sectional areas of $888 \mathrm{~mm}^{2}, 1152 \mathrm{~mm}^{2}$, and $1400 \mathrm{~mm}^{2}$, the corresponding vertical peak loads are $184.2 \mathrm{kN}$, $230.4 \mathrm{kN}$, and $272.6 \mathrm{kN}$, respectively, and the increase rate is about $25 \%$ and $48 \%$. The analytical results show that the vertical bearing capacity of the composite beam can be effectively improved by increasing the cross-sectional area of the lower chords. 
4.4. Spacing of Truss Joint. The influence of different truss joint spacing $(s)$ on the load-deflection $(P-\Delta)$ curves for square steel tube truss concrete beams is given in Figure $8(\mathrm{~d})$. When the spacing is $200 \mathrm{~mm}, 250 \mathrm{~mm}$, and $500 \mathrm{~mm}$, the calculated $P-\Delta$ curves are similar in the shape with almost no difference. The peak values of vertical loads reach $147.3 \mathrm{kN}, 147.2 \mathrm{kN}$, and $145.2 \mathrm{kN}$, respectively, with a slight decrease. It can be stated that the variation of truss joint spacing had almost no impact on the vertical load-carrying capacity.

\section{Flexural Capacity of Normal Section}

5.1. Basic Assumptions. To simplify analysis and facilitate engineering applications, the following assumptions are made: (1) a section remains a plane before and after bending. (2) The grouting material is equivalent to concrete. (3) The tensile strength of concrete is neglected. (4) The constitutive relation of concrete is the same as that used in GB50010-2010 for the flexural capacity of reinforced concrete beams. (5) For steel tubes of upper and lower chords, the average stress is the product of the average strain and modulus of elasticity which cannot exceed its yield strength.

5.2. Calculation Sketch and Formula. Through experiment and calculation, it can be seen that the steel tubes of lower chords for composite beams reached the yield strength first, and the concrete in the compression zone was crushed subsequently. Due to the structural requirements, the upper chords generally cannot completely yield, thus the corresponding average stress can be expressed by $\sigma_{a}^{\prime}$. Figure 9 gives the sketch for calculating flexural capacity $M_{u}$ of the normal section. Here, the stress pattern of concrete in the compression zone can be equivalent to a rectangle with a stress of $\alpha_{1} f_{c} ; \alpha_{1}$ is the ratio of equivalent concrete compressive strength to concrete axial compressive strength; $f_{a}$ is the yield strength of lower chords; $b$ and $h$ are the width and depth of the cross-section, respectively; $h_{0}$ is the effective depth of the cross-section that is the distance from the centroid of the lower chords to the compression edge; $a_{a}^{\prime}$ is the distance from the centroid of the upper chords to the compression edge; $x$ is the depth of compression zone.

$$
\begin{gathered}
f_{a} A_{a}-\sigma_{a}^{\prime} A_{a}^{\prime}-\alpha_{1} f_{c} b x=0, \\
\frac{M_{u}}{\lambda}=\sigma_{a}^{\prime} A_{a}^{\prime}\left(h_{0}-a_{a}^{\prime}\right)+a_{1} f_{c} b x\left(h_{0}-0.5 x\right), \\
\sigma_{a}^{\prime}=E_{a} \varepsilon_{c u}\left(1-\frac{\beta a_{a}^{\prime}}{x}\right) \leq f_{a}, \\
x \leq \xi_{b} h_{0} .
\end{gathered}
$$

The previous tests indicated that, by using the same reinforcement areas and strength, the flexural capacity of composite beams which are reinforced with steel truss will be greater than that of ordinary reinforced concrete beams, and thus an amplifying factor $\lambda$ is usually introduced to predict the flexural capacity [18]. Therefore, force and bending moment equilibrium equation (3) and (4) can be established according to Figure 9, in which $\sigma_{a}^{\prime}$ is calculated according to formula (5), where $\beta$ is the ratio of the depth of compression zone to the actual one, and $\varepsilon_{\mathrm{cu}}$ is the concrete ultimate compressive strain. In order to prevent over-reinforcement failure, the depth $x$ of the compression zone should meet the requirements of expression (6), where $\xi_{b}$ is the relative balanced depth of the compression zone.

On the basis of FEA calculations and tests, the relation of amplifying factor $\lambda$ of flexural capacity and steel ratio $\rho_{a}$ of lower chords is illustrated in Figure 10. By regression analysis, the coefficient $\lambda$ can be calculated as follows:

$$
\lambda=0.766 \rho_{a}^{-0.136} \text {. }
$$

5.3. Comparison of Flexural Capacity of Normal Section. The comparison of the tested value $M_{u}{ }^{t}$, simulated value $M_{u}{ }^{s}$ by FEA models, and calculated value $M_{u}{ }^{c}$ by equation (4) for the flexural capacity of composite beams is shown in Table 3. The ratios $M_{u}{ }^{c} / M_{u}{ }^{t}$ and $M_{u}{ }^{c} / M_{u}{ }^{s}$ are in the range of 0.94 to 1.09 , which indicates that the formula for predicting the flexural capacity of normal sections proposed in this paper are corresponding with the tested and simulated results.

\section{Discussion}

The test and FEA methods in this paper mainly focused on the flexural performance of square steel tube truss concrete beams with grouted chords subjected to under-reinforced failure. Based on the calculation method of the flexural capacity of normal sections for this kind of composite beam was established, and the relation between the amplifying factor $\lambda$ of bending bearing capacity and the steel ratio $\rho_{a}$ of lower chords was put forward. However, due to the limited number of tests and FEA models, the steel ratio of the lower chords in this study was only within the range of $1.13 \%-$ $2.59 \%$, and the influence of the yield of the upper chords on the amplifying factor $\lambda$ of bending capacity was also not considered. In addition, the design formula of crack width and short-term stiffness of this type of composite beam has not been proposed due to unsatisfactory crack simulation and predicted load-deflection curves. Therefore, an indepth study should be carried out in combination with test results. 


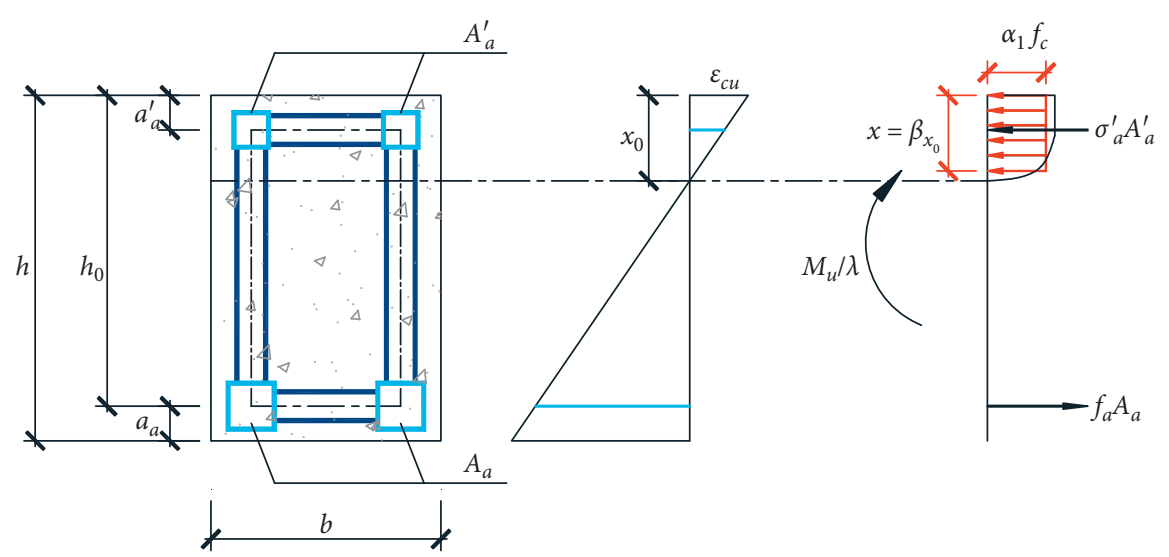

FIgURE 9: Calculation of flexural capacity of normal section.

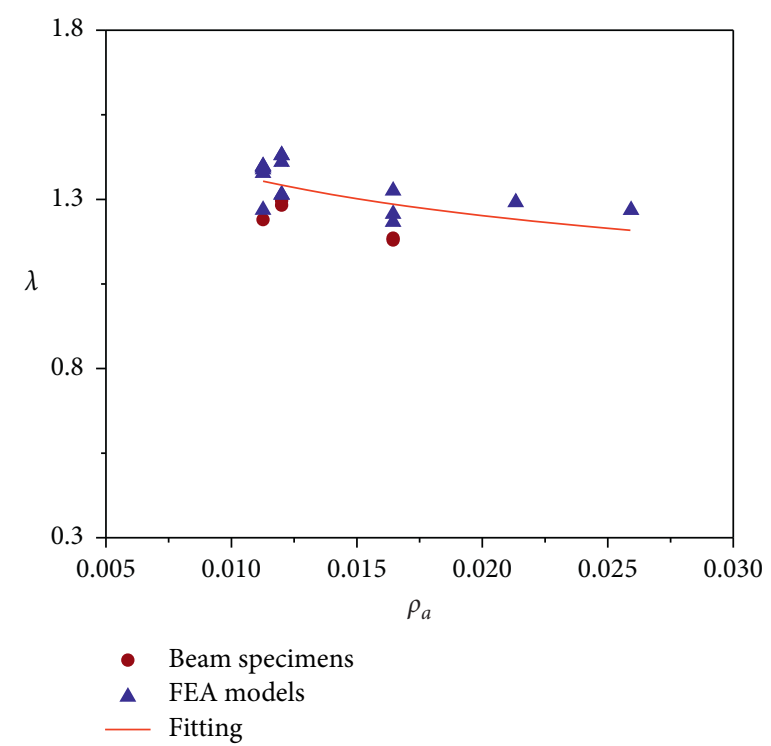

Figure 10: Relation of amplifying factor $\lambda$ and steel ratio $\rho_{a}$.

TABLE 3: Comparison of flexural capacities for tests, simulation, and formula.

\begin{tabular}{|c|c|c|c|c|c|c|}
\hline Serial number & $\rho_{a}(\%)$ & $M_{u}^{t}(\mathrm{kN} \cdot \mathrm{m})$ & $M_{u}^{s}(\mathrm{kN} \cdot \mathrm{m})$ & $M_{u}^{c}(\mathrm{kN} \cdot \mathrm{m})$ & $M_{u}^{c} / M_{u}^{t}$ & $M_{u}^{c} / M_{u}^{s}$ \\
\hline B-1 & 1.13 & 69.4 & 69.5 & 74.2 & 1.07 & 1.07 \\
\hline B-2 & 1.20 & 72.8 & 74.5 & 76.1 & 1.05 & 1.02 \\
\hline B-3 & 1.64 & 81.8 & 85.8 & 89.5 & 1.09 & 1.04 \\
\hline B-4 & 1.64 & 82.5 & 87.5 & 89.5 & 1.08 & 1.02 \\
\hline B-5 & 1.20 & 73.5 & 74.5 & 76.1 & 1.04 & 1.02 \\
\hline CB-1 & 1.13 & - & 50.6 & 49.1 & - & 0.97 \\
\hline CB-2 & 1.13 & - & 51.6 & 50.0 & - & 0.97 \\
\hline $\mathrm{CB}-3$ & 1.13 & - & 52.4 & 50.8 & - & 0.97 \\
\hline CB- 4 & 1.13 & - & 50.0 & 49.1 & - & 0.98 \\
\hline CB-5 & 1.13 & - & 50.4 & 49.1 & - & 0.98 \\
\hline CB-6 & 1.13 & - & 50.6 & 49.1 & - & 0.97 \\
\hline $\mathrm{CB}-7$ & 1.64 & - & 69.1 & 67.0 & - & 0.97 \\
\hline CB-8 & 2.13 & - & 86.4 & 83.0 & - & 0.96 \\
\hline CB-9 & 2.59 & - & 102.2 & 97.4 & - & 0.95 \\
\hline CB-10 & 1.20 & - & 55.2 & 51.8 & - & 0.94 \\
\hline CB-11 & 1.20 & - & 55.2 & 51.8 & - & 0.94 \\
\hline CB-12 & 1.20 & - & 54.5 & 51.8 & - & 0.95 \\
\hline
\end{tabular}




\section{Conclusions}

(1) The established FEA models could well reflect the vertical load-carrying capacities and failure modes for steel tube truss concrete beams with grouted chords. The under-reinforced failure was observed, where the lower chords reached tensile yield, and subsequently, the upper concrete was crushed.

(2) With an increase of the steel ratio of the lower chord steel tubes, the vertical load-carrying capacity of the square steel tube truss concrete beam increased, whereas the concrete strength, steel ratio of the upper chord steel tubes, and truss joint spacing had little effect on the vertical load-carrying capacity.

(3) The predicting flexural capacity of composite beams by proposed formulae is in agreement with the tested and FEA results, which could be applied in engineering design.

\section{Data Availability}

The data used to support the findings of this study are available from the corresponding author upon request.

\section{Conflicts of Interest}

The authors declare that they have no conflicts of interest.

\section{Acknowledgments}

The authors appreciate the support of the National Science Foundation of China (51878589), China Postdoctoral Science Foundation (2019M651762), Six Talent Peaks Project of Jiangsu Province (2017-JZ-038), Science and Technology Planning Project of Yangzhou City (YZ2018068), and Project of Innovation and Entrepreneurship Plan of Jiangsu Province (2019).

\section{References}

[1] W. Z. Zheng, G. M. Zhang, X. D. Liu, and B. Y. Zhang, "Experimental research on ultimate bearing capacity of $N$ joints of grouted square steel tube trusses," Journal of Southeast University (English Edition, vol. 23, no. 4, pp. 566-570, 2007.

[2] W. Z. Zheng, X. D. Liu, B. Y. Zhang, and G. M. Zhang, "Experimental research on cave-in ultimate bearing capacity of grouted-round-steel tube," Journal of Architectural Structure, vol. 29, no. 2, pp. 85-91, 2008, in Chinese.

[3] W. Huang, Z. Lai, B. Chen, and P. Yao, "Experimental behavior and analysis of prestressed concrete-filled steel tube (CFT) truss girders," Engineering Structures, vol. 152, pp. 607-618, 2017.

[4] Y.-H. Huang, A.-R. Liu, J.-Y. Fu, and Y.-L. Pi, "Experimental investigation of the flexural behavior of CFST trusses with interfacial imperfection," Journal of Constructional Steel Research, vol. 137, pp. 52-65, 2017.

[5] Z.-q. Fu, B.-h. Ji, W. Zhu, and H.-b. Ge, "Bending behaviour of lightweight aggregate concrete-filled steel tube spatial truss beam," Journal of Central South University, vol. 23, no. 8, pp. 2110-2117, 2016.

[6] W. Z. Zheng, X. D. Liu, and B. Y. Zhang, "Experimental study on composite beam of grouting round steel tube truss-concrete," Journal of Architectural Structure, vol. 20, no. 1, pp. 15-22, 2009.

[7] W. Zheng, K. Wang, and G. Zhang, "Experimental study on hysteretic behavior of prestressed truss concrete composite beams," Earthquake Engineering and Engineering Vibration, vol. 9, no. 1, pp. 65-74, 2010.

[8] B. Y. Zhang, W. Z. Zheng, and Z. G. Yuan, "Mechanical properties of truss concrete composite beam prestressed encased with circular steel tubes," Journal of Jilin University (Engineering and Technology Edition), vol. 38, no. 3, pp. 636-641, 2008, in Chinese.

[9] Z. H. Deng, K. Chen, and C. Feng, "Experimental study on bending resistance of truss steel reinforced concrete beams," Industrial Construction, vol. 45, no. 12, pp. 178-182, 2015, in Chinese.

[10] L. G. Wang and G. B. Mu, "Research on bending performance of prestressed lattice Type steel reinforced concrete beam," Engineering Mechanics, vol. 28, no. 8, pp. 113-118, 2011, in Chinese.

[11] M. Arafa, M. A. Alqedra, and R. Salim, "Performance of RC beams with embedded steel trusses using nonlinear FEM analysis," Advances in Civil Engineering, vol. 2018, Article ID 9079818, 8 pages, 2018.

[12] P. Colajanni, L. La Mendola, and A. Monaco, "Stress transfer and failure mechanisms in steel-concrete trussed beams: experimental investigation on slab-thick and full-thick beams," Construction and Building Materials, vol. 161, pp. 267-281, 2018.

[13] Y. Y. Chen, J. C. Dong, Z. J. Tong et al., "Flexural behavior of composite box girders with corrugated steel webs and trusses," Engineering Structures, vol. 209, Article ID 110275, 2020.

[14] K. Hibbitt and Sorensen Inc, ABAQUS/standard User's Manual, Version 6.4.1, Hibbitt, Karlsson, and Sorensen Inc, Pawtucket, RI, USA, 2003.

[15] GB50010-2010, Code for Concrete Structure Design, China Building Industry Press, Beijing, China, 2010, in Chinese.

[16] G. M. Zhang, Study on the Basic Problems of Prestressed Concrete Composite Beams with Built-In Grouting Square Steel Tube Truss, Harbin Institute of Technology, Harbin, China, 2008, in Chinese.

[17] GB/T 50152-2012, Standard Test Methods for Concrete Structures, China Building Industry Press, Beijing, China, 2012, in Chinese.

[18] H. T. Zhao, Steel \& Concrete Composite Structure, Science press, Beijing, China, 2001, in Chinese. 